ORIGINAL ARTICLE

\title{
A prospective study of injuries and training amongst the England 2003 Rugby World Cup squad
}

\author{
J H M Brooks, C W Fuller, S P T Kemp, D B Reddin
}

Br J Sports Med 2005;39:288-293. doi: 10.1136/bjsm.2004.013391

See end of article for authors' affiliations

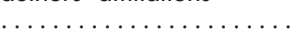

Correspondence to: Dr Colin W Fuller,

University of Leicester,

Scarman Centre, 154

Upper New Walk,

Leicester LE1 7QA, UK;

cwf2@le.ac.uk

Accepted 29 July 2004

\begin{abstract}
Objectives: To assess the aetiology, incidence, severity, and causes of injuries to England rugby union players during preparation for and participation in the 2003 Rugby World Cup.

Method: A 63 week prospective design was employed to study the training practices and injuries of England rugby players. The team physician reported all training and match injuries and provided details of the location, diagnosis, severity, and mechanism of each injury. The team fitness coach reported details of the number and duration of training sessions and the time dedicated to rugby and conditioning training. Players' stature, body mass, and skinfolds were measured at the beginning and end of the study period. Results: The overall incidence of injury was 17 injuries/1000 h of exposure (match: 218 injuries/1000 h; training: 6.1 injuries/1000 h). The major locations of injuries were the lower (60\%) and upper (17\%) limbs and the most common diagnoses were muscle and tendon (50\%) and joint (non-bone) and ligament (41\%) injuries. The highest incidences of match injuries occurred whilst being tackled (50 injuries/1000 h) and in a ruck or maul (35 injuries/1000 h), whilst the greatest incidences of training injuries occurred during endurance running (24 injuries/1000 h) and contact activities (20 injuries/1000 h). Players' average body mass increased and skinfold measurement decreased significantly over the study period.

Conclusions: The incidence of match injuries at international level was found to be higher than previously reported. The tackle, ruck, and maul elements of match play and the endurance running and contact elements of training presented the highest risk of injury for all players.
\end{abstract}

$\mathrm{R}$ ugby union, which is the most popular worldwide team contact sport involving collision, ${ }^{1}$ has one of the highest levels of injury of all team sports. ${ }^{2}$ Whilst there have been several epidemiological studies of injuries in rugby union at the amateur level, ${ }^{3}{ }^{4}$ the number of prospective studies amongst elite players is small. Targett ${ }^{5}$ presented a study of 25 professional players in a New Zealand Super 12 team over a 6 month period (15 games) and reported an incidence of 120 injuries per 1000 player-hours of exposure. Jakoet and Noakes ${ }^{6}$ described a study of the 16 teams in the 1995 Rugby World Cup in South Africa (55 games) and reported an incidence of 32 injuries per 1000 player-hours. Bathgate et $\mathrm{al}^{7}$ presented a study of the Australian Wallabies over the period 1994 to 2000 (91 games) and reported an incidence of 69 injuries per 1000 player-hours. Although two of the previous studies ${ }^{5}$ reported numbers of training injuries, none of the studies reported the incidence of injuries in training. The differences in the reported incidence values highlight the importance of using a consistent methodology for epidemiological studies and, in particular, a consistent definition of injury. ${ }^{8}$ In the earlier studies, an injury was defined by Targett ${ }^{5}$ as something that prevented a player from taking part in two training sessions or caused a player to miss a match; by Jakoet and Noakes ${ }^{6}$ as a new injury that necessitated a player leaving the field of play; and by Bathgate $\mathrm{et}^{\mathrm{al}}$ as one that forced a player to leave the field of play or miss the next match. Noyes et al ${ }^{9}$ recommended that, if injuries only required the use of ice and bandaging, they should be excluded from epidemiological studies, whereas Luthje et al $^{10}$ argued for all injuries requiring medical attention to be included because even minor injuries could affect an athlete's long term physical and mental condition. An advantage of categorising all player complaints that require medical attention as an injury is that incidences of injury can then be compared across all sports. A disadvantage of this approach, however, is that the inclusion of large numbers of injuries, such as minor contusions and cuts, can place an overwhelming burden on physicians taking part in epidemiological studies in some contact sports. ${ }^{11}$ The importance of reporting the incidence ${ }^{12}$ and severity ${ }^{13}{ }^{14}$ of injuries in epidemiological studies has been emphasised in order to assess causal links between risk factors and injuries and to inform decisions on preventive and therapeutic interventions.

The aims of the research were to determine the aetiology, incidence, severity, and causes of injuries suffered by the England rugby union squad during their preparation for and participation in the 2003 Rugby World Cup in Australia.

\section{METHOD}

The method employed was a prospective study of the injuries and training practices of all players (forwards: $\mathrm{n}=32$; backs: $\mathrm{n}=31$ ) involved with the England squad during the 2002/ 2003 season and whilst they prepared for and participated in the 2003 Rugby World Cup. All players signed a consent form for their medical data to be collected and utilised in the study.

\section{Phases of the epidemiological study}

The epidemiological study covered 37 weeks of training and competition within an overall period of 63 weeks, which culminated in the 2003 Rugby World Cup Final between England and Australia. The study period was split into three phases for assessment. The first phase (pre-World Cup) extended from September 2002 to June 2003 (19 weeks) during which time the players competed for England and attended training sessions with the England coaching and fitness staff; when players were not training or competing with the national squad, they undertook their normal club rugby commitments (not included within this paper). The second phase (Rugby World Cup training camp) extended from July to September 2003 ( 10 weeks) during which time the players worked full time with the England coaching and fitness staff on personalised conditioning and team rugby 
Table 1 Anthropometric data (mean and standard deviation) of the study population (forwards: $n=30 ;$ backs: $n=23$ )

\begin{tabular}{|c|c|c|c|c|c|c|}
\hline & \multicolumn{3}{|c|}{ September 2002} & \multicolumn{3}{|c|}{ September 2003} \\
\hline & Stature, $m$ & Body mass, kg & Skinfold, mm & Stature, $m$ & Body mass, kg & Skinfold, mm \\
\hline $\begin{array}{l}\text { Forwards } \\
\text { Backs }\end{array}$ & $\begin{array}{l}1.88(0.08) \\
1.81(0.05)\end{array}$ & $\begin{array}{r}106.4(8.7) \\
88.4(5.4)\end{array}$ & $\begin{array}{l}36.2(13.8) \\
26.4(5.0)\end{array}$ & $\begin{array}{l}1.88(0.08) \\
1.81(0.05)\end{array}$ & $\begin{array}{r}108.9(8.7) \\
90.4(5.5)\end{array}$ & $\begin{array}{l}31.5(8.5) \\
25.4(4.5)\end{array}$ \\
\hline
\end{tabular}

training and competed in warm up matches. The final phase (Rugby World Cup) extended from October to November 2003 (8 weeks) during which time the players worked full time with the England coaching and fitness staff and competed in the World Cup.

\section{Injury assessment}

The injury definition adopted for this study was based on time lost from training and/or competition and was similar to the definition adopted previously by one of the authors (CF) for studies within professional football (soccer), ${ }^{15}$ namely, "any injury that prevented a player from taking a full part in all training activities typically planned for that day and match play for a period equal to or greater than $24 \mathrm{~h}$, from midnight of the day the injury was sustained". Absence from training or competition through illness or other medical conditions was excluded from the study. All injuries were diagnosed and reported on a standard injury report form by the England team physician (SK), who attended all training sessions and matches. Each report provided information on the date, time, activity involved, and mechanism of injury, the date of return to full training/competition, and the number of matches missed as a result of the injury. A clinical judgement was made by the team physician as to whether the injury was recurrent. Reporting of the location and diagnosis of injuries was based on the Orchard Sports Injury Classification System. ${ }^{16}$ A secondary injury definition, "significant injury", which covered all injuries resulting in a player missing at least one competitive match, was also included in order that results from this study can be compared with previous studies where this definition was adopted. Injury severity was defined as the total number of days that a player was unavailable for full training and competition.

\section{Training programmes}

All training programmes were reported on a standard training report form by the England fitness coach (DR), who attended all training sessions and matches. Each report provided information on the number and duration of training sessions and the time dedicated to rugby (team play/phase work and individual/team skills) and conditioning training (weights, endurance, and speed/agility) and fitness testing. Training exposure for each player was recorded; however, no attempt was made to quantify the intensity of training undertaken by each player.
Table 3 The most frequent and most severe injury diagnoses

\begin{tabular}{lll}
\hline Injury category & Number & Average severity (days) \\
\hline Most frequent injuries & & \\
Hamstring muscle injury* & 14 & 11 \\
Calf muscle injury* & 12 & 11 \\
Thigh haematoma & 10 & 3 \\
Shoulder joint sprain & 8 & 6 \\
Ankle lateral ligament & 8 & 9 \\
Calf/shin haematoma & 6 & 4 \\
Knee joint sprain/jar & 6 & 20 \\
Cervical facet joint & 5 & 3 \\
Rib fracture/contusion & 5 & 6 \\
Adductor muscle injury* & 5 & 8 \\
Most severe injuries & & \\
Anterior cruciate ligament & 1 & 235 \\
Knee cartilage/ & 1 & 155 \\
degenerative injury & & \\
Rotator cuff/shoulder & 3 & 71 \\
impingement & & \\
Cervical disc & 1 & 45 \\
Thoracic facet joint & 3 & 35 \\
\hline *Excluding haematomas/contusions. &
\end{tabular}

\section{Anthropometric measurements}

The stature, body mass, and sum of four skinfolds ${ }^{17}$ were measured for each player during September 2002 and again during September 2003.

\section{Data analysis}

Paired sample t tests were used to identify differences in stature, body mass, and sum of skinfolds for forwards and backs as a function of the date of measurement. $\chi^{2}$ Tests were used to identify differences in the diagnosis and location of injuries as functions of playing position and activity at the time of injury. The $\mathrm{Z}$ test was used for assessing differences in the incidence of injury between forwards and backs and training and matchplay. Statistical significance was accepted at $\mathrm{p}<0.05$ in all cases.

\section{RESULTS}

Table 1 shows the average anthropometric measurements for the forwards and backs at the beginning and end of the study. There were significant differences over this period in body mass for forwards $(\mathrm{p}<0.001)$ and backs $(\mathrm{p}<0.001)$ and

Table 2 Aetiology of injury as a function of location and diagnosis

\begin{tabular}{llcccr}
\hline & \multicolumn{4}{l}{ Injury location: number of injuries (average severity, days) } \\
\cline { 2 - 6 } Injury diagnosis & Head/neck & Upper limb & Trunk & Lower limb & All \\
\hline Fractures and bone stress & $1(33)$ & $1(21)$ & $0(-)$ & $1(20)$ & $3(25)$ \\
Joint (non-bone) and ligament & $6(3)$ & $17(6)$ & $12(18)$ & $25(27)$ & $60(17)$ \\
Muscle and tendon & $0(-)$ & $6(17)$ & $6(7)$ & $60(9)$ & $72(11)$ \\
Laceration and skin & $2(6)$ & $0(-)$ & $0(-)$ & $0(-)$ & $2(6)$ \\
Central/peripheral nervous system & $7(17)$ & $0(-)$ & $0(-)$ & $1(3)$ & $8(16)$ \\
All & $16(12)$ & $24(14)$ & $18(14)$ & $87(14)$ & $145(14)$ \\
\hline
\end{tabular}


Table 4 Injury location as a function of playing position (forwards: $n=32$; backs: $n=31$ )

\begin{tabular}{|c|c|c|c|c|}
\hline \multirow[b]{3}{*}{ Injury location } & \multicolumn{4}{|c|}{ Number $(\%)$ and average severity (days) of injuries } \\
\hline & \multicolumn{2}{|l|}{ Forwards } & \multicolumn{2}{|l|}{ Backs } \\
\hline & No. (\%) & Severity & No. (\%) & Severity \\
\hline Head/neck & $7(10)$ & 15 & 9 (12) & 9 \\
\hline Upper limb & 13 (19) & 21 & $11(14)$ & 7 \\
\hline Trunk & 11 (16) & 13 & 7 (9) & 16 \\
\hline Lower limb & $36(54)$ & 16 & $51(65)$ & 13 \\
\hline All & $67(100)$ & 17 & $78(100)$ & 12 \\
\hline
\end{tabular}

Table 5 Injury diagnosis as a function of playing position (forwards: $n=32$; backs: $n=31$ )

\begin{tabular}{|c|c|c|c|c|}
\hline \multirow[b]{3}{*}{ Injury diagnosis } & \multicolumn{4}{|c|}{ Number (\%) and average severity (days) of injuries } \\
\hline & \multicolumn{2}{|l|}{ Forwards } & \multicolumn{2}{|l|}{ Backs } \\
\hline & No. $(\%)$ & Severity & No. $(\%)$ & Severity \\
\hline $\begin{array}{l}\text { Fractures and bone } \\
\text { stress }\end{array}$ & $3(4)$ & 25 & $0(0)$ & - \\
\hline $\begin{array}{l}\text { Joint (non-bone) } \\
\text { and ligament }\end{array}$ & $27(40)$ & 17 & $33(42)$ & 17 \\
\hline Muscle and tendon & $32(48)$ & 16 & $40(51)$ & 8 \\
\hline Laceration and skin & $1(1)$ & 5 & $1(1)$ & 6 \\
\hline $\begin{array}{l}\text { Central/peripheral } \\
\text { nervous system }\end{array}$ & $4(6)$ & 16 & $4(5)$ & 16 \\
\hline All & $67(100)$ & 17 & $78(100)$ & 12 \\
\hline
\end{tabular}

in skinfold measurement for forwards $(\mathrm{p}<0.01)$ but not for backs $(\mathrm{p}<0.20)$.

There were 145 injuries (match: 97; training: 48) reported during the study period (pre-World Cup: 67; training camp: 37; Rugby World Cup: 41) of which 22 were recurrent injuries. The average severity of all injuries was 14 days (new injuries: 12 days; recurrent injuries: 28 days). Table 2 provides an overview of the distribution and severity of these injuries in terms of location and diagnosis and table 3 lists the diagnoses of the 10 most frequent and the five most severe injuries. Only three concussions (average severity: 7 days) were recorded throughout the study period. There were no significant differences in the distributions of injury location $(\mathrm{p}<0.38)$ (table 4$)$, diagnosis $(\mathrm{p}<0.45)$ (table 5$)$, and activity $(\mathrm{p}<0.68)$ (table 6$)$ as a function of playing position (forwards: 67; backs: 78). There were also no significant differences in the distributions for injury location $(p<0.09)$ (table 7 ) and diagnosis $(\mathrm{p}<0.27)$ (table 8 ) as a function of the activity at the time of injury (match: 97; training: 48). There were 47 "significant injuries" (match: 26; training: 21 ).

The players competed in 22 matches (pre-World Cup: 12; training camp: 3; Rugby World Cup: 7) during the 63 week

Table 6 Injuries as a function of activity and playing position (forwards: $n=32$; backs: $n=31$ )

\begin{tabular}{|c|c|c|c|c|}
\hline \multirow[b]{3}{*}{ Activity } & \multicolumn{4}{|c|}{ Number $(\%)$ and average severity (days) of injuries } \\
\hline & \multicolumn{2}{|l|}{ Forwards } & \multicolumn{2}{|l|}{ Backs } \\
\hline & No. $(\%)$ & Severity & No. (\%) & Severity \\
\hline Match & $46(69)$ & 17 & $51(65)$ & 11 \\
\hline Training & $21(31)$ & 16 & $27(35)$ & 13 \\
\hline All & $67(100)$ & 17 & $78(100)$ & 12 \\
\hline
\end{tabular}

Table 7 Injury location as a function of activity at the time of injury (forwards: $n=32$; backs: $n=31$ )

\begin{tabular}{|c|c|c|c|c|}
\hline \multirow[b]{3}{*}{ Injury location } & \multicolumn{4}{|c|}{ Number (\%) and average severity (days) of injuries } \\
\hline & \multicolumn{2}{|l|}{ Match } & \multicolumn{2}{|l|}{ Training } \\
\hline & No. $(\%)$ & Severity & No. $(\%)$ & Severity \\
\hline Head/neck & $14(14)$ & 13 & $2(4)$ & 4 \\
\hline Upper limb & $19(20)$ & 16 & $5(10)$ & 8 \\
\hline Trunk & $11(11)$ & 6 & 7 (15) & 28 \\
\hline Lower limb & $53(55)$ & 16 & $34(71)$ & 13 \\
\hline All & $97(100)$ & 14 & $48(100)$ & 14 \\
\hline
\end{tabular}

period. The total exposure time was 8373 player-hours (match: 445; training: 7928) and the overall incidence of injury was 17 injuries/1000 player-hours (match: 218; training: 6.1 and forwards: 15; backs: 21). The overall incidence of "significant injuries" was 5.6 injuries/1000 player-hours (match: 58; training: 2.6). Table 9 shows the incidence and average severity of injuries as a function of playing position, activity at the time of injury, and the phase of preparation for the World Cup. Table 10 shows the incidence of injury as a function of injury severity. The major sources of match injuries (table 11) were being tackled (23\%) and rucking and mauling (16\%), which equated to 50 and 35 injuries/1000 h, respectively.

The number and average duration of training sessions undertaken by forwards and backs are shown in table 12, whilst the structure of the training programmes, as a function of the phase of the World Cup preparation and playing position, is shown in table 13. A subjective assessment identified that the highest training intensity occurred during the training camp. Table 14 presents the number and incidence of injuries as a function of each element of the training programme for forwards and backs. For forwards, $68 \%$ of endurance training involved off-feet exercise, such as rowing and cycling, whereas for backs, 95\% involved running activities.

\section{DISCUSSION}

The issue of injury definition is contentious within epidemiological studies and difficulties can arise when making comparisons between studies if different definitions of injury are used. ${ }^{18} 19$ Definitions similar to the one adopted in this study have been used previously in both individual studies, such as soccer, ${ }^{15}{ }^{20}$ volleyball, ${ }^{21}$ and basketball, ${ }^{22}$ and in large scale national audits of sports injuries, such as the Football Association in England for professional soccer, ${ }^{23}$ the New Zealand Rugby Injury Audit and Performance Project for

Table 8 Injury diagnosis as a function of activity at the time of injury (forwards: $n=32$; backs: $n=31$ )

\begin{tabular}{|c|c|c|c|c|}
\hline \multirow[b]{3}{*}{ Injury diagnosis } & \multicolumn{4}{|c|}{ Number (\%) and average severity (days) of injuries } \\
\hline & \multicolumn{2}{|l|}{ Match } & \multicolumn{2}{|l|}{ Training } \\
\hline & No. $(\%)$ & Severity & No. $(\%)$ & Severity \\
\hline $\begin{array}{l}\text { Fractures and bone } \\
\text { stress }\end{array}$ & $3(3)$ & 25 & $0(0)$ & - \\
\hline $\begin{array}{l}\text { Joint (non-bone) } \\
\text { and ligament }\end{array}$ & $41(42)$ & 16 & $19(40)$ & 20 \\
\hline Muscle and tendon & $44(45)$ & 12 & $28(58)$ & 11 \\
\hline Laceration and skin & $2(2)$ & 6 & $0(0)$ & - \\
\hline $\begin{array}{l}\text { Central/peripheral } \\
\text { nervous system }\end{array}$ & $7(7)$ & 17 & $1(2)$ & 5 \\
\hline All & $97(100)$ & 14 & $48(100)$ & 14 \\
\hline
\end{tabular}


Table 9 Incidence and severity of injuries as a function of playing position, activity, and phase of preparation for the Rugby World Cup (forwards: $n=32$; backs: $n=31$ )

\begin{tabular}{|c|c|c|c|c|c|}
\hline \multirow[b]{3}{*}{ Phase of preparation } & \multicolumn{5}{|c|}{ Incidence of injuries $/ 1000 \mathrm{~h}$ (average severity, days) } \\
\hline & \multicolumn{2}{|l|}{ Match } & \multicolumn{2}{|l|}{ Training } & \multirow[b]{2}{*}{ Overall } \\
\hline & Forwards & Backs & Forwards & Backs & \\
\hline Pre-World Cup & $242(20)$ & 197 (18) & $5.0(20)$ & $5.0(7)$ & $20(18)$ \\
\hline Training camp & $63(19)$ & $287(13)$ & $7.2(14)$ & 9.1 (19) & $11(16)$ \\
\hline Rugby World Cup & $168(9)$ & $312(4)$ & $1.3(4)$ & $9.4(6)$ & $27(6)$ \\
\hline All phases & 194 (17) & 246 (11) & $4.8(16)$ & $7.6(13)$ & $17(14)$ \\
\hline
\end{tabular}

rugby union, ${ }^{3}$ and the NCAA Injury Surveillance System ${ }^{24}$ in the United States. The definition of injury adopted within this study therefore enables data to be compared effectively across different studies and different sports.

The epidemiological studies reported by Bathgate et al ${ }^{7}$ and Jakoet and Noakes ${ }^{6}$ represent the closest studies to the present one in terms of sample population, whereas the study by Targett ${ }^{5}$ represents the closest in terms of injury definition. There were no incidence values reported for training injuries in these studies to compare with the incidence in the present study (6.1/1000 player-hours). The incidence of match injuries observed in this study (218/1000 player-hours) was nearly twice that reported by Targett, ${ }^{5}$ three times that reported by Bathgate et al, ${ }^{7}$ and seven times that reported by Jakoet and Noakes. ${ }^{6}$ The higher incidence of match injury observed in the present study can be explained in part by the $30 \%$ increase in the "ball in play" times reported for the 2003 Rugby World Cup compared to the 1995 Rugby World Cup ${ }^{25}$ : this longer time in play would increase the players' risk exposure proportionately. The wider definition of injury adopted in the present study compared to previous studies and the efficient injury reporting regime implemented, as the team doctor was present at every training session and match, were also likely to contribute to the higher values reported here. A further contributory factor may be the increase in players' body mass ${ }^{26}$ and/or fat-free body mass ${ }^{27}$ observed in the present study compared to previous measurements on British international rugby union players.

The distribution of injury diagnoses in the present study was different from those reported previously: this was caused in the main by the different definitions of injury. In previous studies, ${ }^{5-7}$ facial lacerations formed a major proportion (12$19 \%$ ) of the reported injuries, as this type of injury resulted in players leaving the field of play for treatment. Although players were also required to leave the field of play in the present study for the treatment of lacerations under the International Rugby Board ${ }^{28}$ "blood injury" law, these injuries did not, in general, prevent the players from continuing to play after treatment or from taking part in training sessions and matches: consequently, this type of injury was excluded from the present study. There were differences in the distribution of injury locations between the

\begin{tabular}{|c|c|c|c|}
\hline \multirow[b]{2}{*}{ Injury mechanism } & \multicolumn{3}{|c|}{ Number of injuries (\%) } \\
\hline & Forwards & Backs & All \\
\hline Tackled & $10(22)$ & $12(24)$ & $22(23)$ \\
\hline Tackling & $6(13)$ & 7 (14) & $13(13)$ \\
\hline Ruck/maul & $10(22)$ & 6 (12) & $16(16)$ \\
\hline Set piece & $5(11)$ & $0(0)$ & $5(5)$ \\
\hline Running & $3(7)$ & $7(14)$ & $10(10)$ \\
\hline Collision & $3(7)$ & $5(10)$ & $8(8)$ \\
\hline Kicking & 0 (0) & $1(2)$ & 1 (1) \\
\hline Twisting/turning & $0(0)$ & $3(6)$ & $3(3)$ \\
\hline Other/not identified & $9(20)$ & $10(20)$ & $19(20)$ \\
\hline
\end{tabular}

present and previous studies because lacerations to the head formed a major proportion of injuries in previous studies, ${ }^{5-7}$ but these were also largely excluded from the present study for the reason given above. The present study provided a detailed analysis of injury severity as a function of injury diagnosis and location and the playing position and activity at the time of injury. This level of detail was not available in the earlier studies. Two of the previous studies ${ }^{5}$ categorised injuries as mild ( $\leqslant 1$ week absence), moderate $(>1$ to 3 weeks absence) and major ( $>3$ weeks absence) and the results from the present study were similar to these previous results. Although it might have been anticipated that the more inclusive injury definition used in the present study might have increased the reporting of "minor" injuries compared with previous studies, this was not found to be the case. This may be attributable in part to the exclusion from the present study of minor laceration injuries that only resulted in the player leaving the field of play whilst the laceration was treated, whereas in previous studies these injuries were included.

It is not possible to compare the mechanisms of injury in the present study with previous studies as the level of detail provided in the earlier studies was limited: for example, two of the studies ${ }^{5}$ did not differentiate between tackling and being tackled as injury mechanisms. The total proportion of

Table 10 Incidence of injury as a function of injury severity (forwards: $n=32$; backs: $n=31$ )

\begin{tabular}{|c|c|c|c|c|c|c|}
\hline \multirow[b]{3}{*}{ Severity } & \multicolumn{6}{|c|}{ Incidence of injuries/1000 h (number of injuries) } \\
\hline & \multicolumn{3}{|l|}{ Match } & \multicolumn{3}{|l|}{ Training } \\
\hline & Forwards & Backs & All & Forwards & Backs & All \\
\hline$\leqslant 1$ week & $126(30)$ & $169(35)$ & $146(65)$ & $2.3(10)$ & $3.9(14)$ & $3.0(24)$ \\
\hline$>1$ week to 3 weeks & $25(6)$ & 58 (12) & $40(18)$ & $1.8(8)$ & $2.5(9)$ & 2.1 (17) \\
\hline$>3$ weeks & 42 (10) & $19(4)$ & 31 (14) & $0.7(3)$ & $1.1(4)$ & 0.9 (7) \\
\hline
\end{tabular}


Table 12 Training exposures during the three phases of preparation as a function of playing position (forwards: $\mathrm{n}=32$; backs: $\mathrm{n}=31$ )

\begin{tabular}{|c|c|c|c|c|}
\hline \multirow{3}{*}{$\begin{array}{l}\text { Phase of } \\
\text { preparation }\end{array}$} & \multicolumn{4}{|c|}{$\begin{array}{l}\text { Average number and length of training sessions per } \\
\text { week }\end{array}$} \\
\hline & \multicolumn{2}{|l|}{ Forwards } & \multicolumn{2}{|l|}{ Backs } \\
\hline & Number & Length, mins & Number & Length, mins \\
\hline Pre-World Cup & 6 & 87 & 6 & 85 \\
\hline Training camp & 12 & 46 & 12 & 43 \\
\hline Rugby World Cup & 6 & 61 & 6 & 54 \\
\hline
\end{tabular}

injuries in the present study that occurred during the tackle phase $(36 \%)$ was much lower than that reported previously ${ }^{5-7}$ $(46-58 \%)$. Jakoet and Noakes, ${ }^{6}$ who did differentiate between tackling and being tackled, reported a similar proportion of injuries caused by being tackled (29\% v 23\%) but a much higher proportion of injuries caused by tackling $(27 \% v 13 \%)$ than the present study. The lower total proportion of injuries caused within the tackle phase observed in the present study may, therefore, reflect a higher level of injury awareness by players during the tackling element.

From an injury management perspective, there are lessons that can be learnt from the results presented here in terms of the future development of training programmes. During the Pre-World Cup and the Rugby World Cup phases, 75-87\% of training was aimed at the development of individual and team rugby skills in preparation for matches. However, during the training camp $52-55 \%$ of the training was aimed at improving the players' physical condition. The success of the conditioning element of the training programme was indicated by the change in the players' anthropometric measurements as body mass increased whilst skinfold measurements decreased resulting in a significant increase in the players' fat-free body mass over the study period. Whilst the shift in focus from skills training to conditioning training had an impact on the incidence and severity of injuries observed during the training camp, only one player taking part in this phase was unavailable for selection for the World Cup squad through injury and this injury occurred during competition.

The overall incidence of injury during the study period was higher for backs than for forwards, although the average severity of injuries to the backs was lower than that for forwards. There was a consistent decline in the severity and a trend towards a lower incidence of injury amongst forwards for both competition and training over the three phases of the study. For backs, there was an increase in the incidence of
Table 14 Incidence and number of injuries as a function of training element (forwards: $n=32$; backs: $n=31$ )

\begin{tabular}{|c|c|c|c|}
\hline \multirow{2}{*}{ Type of training } & \multicolumn{3}{|c|}{$\begin{array}{l}\text { Incidence of injury per } 1000 \mathrm{~h} \text { (number of } \\
\text { injuries) }\end{array}$} \\
\hline & Forwards & Backs & All \\
\hline \multicolumn{4}{|l|}{ Skills } \\
\hline Contact & $12(4)$ & $41(7)$ & $20(11)$ \\
\hline Non-contact & 3.5 (9) & $5.2(10)$ & 4.2 (19) \\
\hline \multicolumn{4}{|l|}{ Conditioning } \\
\hline Weights & $2.6(2)$ & $1.5(1)$ & 2.1 (3) \\
\hline $\begin{array}{l}\text { Endurance } \\
\text { (running) }\end{array}$ & $38(5)$ & $16(4)$ & $24(9)$ \\
\hline $\begin{array}{l}\text { Endurance } \\
\text { (off-feet) }\end{array}$ & $0(0)$ & $0(0)$ & $0(0)$ \\
\hline $\begin{array}{l}\text { Speed and } \\
\text { agility }\end{array}$ & $0(0)$ & $3.8(1)$ & $2.4(1)$ \\
\hline Fitness testing & $7(1)$ & $29(3)$ & $17(4)$ \\
\hline
\end{tabular}

injury over the three phases of the study for both training and competition and an increase in the severity of injuries during competition. There was, however, a large reduction in the average severity of injuries during competition and this resulted in the risk of absence due to injury (incidence $\times$ severity) being much lower during the Rugby World Cup phase. The incidence and severity of training injuries observed for forwards and backs during the training camp may reflect the accumulative effect of the volume and intensity of training undertaken at this time ${ }^{29}$ : a similar effect has been observed during international football training camps. ${ }^{30}$ The overall reduction in injury severity during competition and the availability of all but one player for the World Cup suggested that the use of personalised conditioning training programmes for developing players' strength and endurance was a successful injury management strategy.

Of particular importance from an injury management perspective was the demonstration that endurance running and contact training represented the highest risk activities. It is possible that the greater stature and body mass of forwards placed them at a higher risk during endurance running. ${ }^{31}$ However, by ensuring that a high proportion $(68 \%)$ of the forward's endurance training involved low risk off-feet endurance exercises, such as rowing and cycling, the overall level of risk within this element of conditioning training was reduced to the lowest levels possible. It may appear that the level of risk could have been reduced even more by further increases in the proportion of off-feet endurance training but taking this approach too far reduces the relevance of the training with respect to the specific demands of the game and would not have prepared the players for the harder ground conditions encountered during the World Cup. It has been

Table 13 Training format during the three phases of preparation as a function of playing position (forwards: $n=32 ;$ backs: $\mathrm{n}=31$ )

\begin{tabular}{|c|c|c|c|c|c|c|}
\hline \multirow[b]{3}{*}{ Type of training } & \multicolumn{6}{|c|}{ Average training time per week per player, mins ( $\%$ of all training) } \\
\hline & \multicolumn{2}{|c|}{ Pre-World Cup } & \multicolumn{2}{|c|}{ Training camp } & \multicolumn{2}{|c|}{ Rugby World Cup } \\
\hline & Forwards & Backs & Forwards & Backs & Forwards & Backs \\
\hline \multicolumn{7}{|l|}{ Skills } \\
\hline Team play/phase work & $45(9)$ & $45(10)$ & $6(1)$ & $6(1)$ & $46(13)$ & $46(14)$ \\
\hline Individual/team skills & $388(78)$ & $356(77)$ & $248(46)$ & $227(44)$ & $226(64)$ & $208(61)$ \\
\hline \multicolumn{7}{|l|}{ Conditioning } \\
\hline Weights & $47(9)$ & $47(10)$ & $146(27)$ & $146(28)$ & $54(15)$ & $54(16)$ \\
\hline Endurance & $8(2)$ & $8(2)$ & 104 (19) & $68(13)$ & $21(6)$ & $23(7)$ \\
\hline Speed and agility & $8(2)$ & $8(2)$ & $33(6)$ & $72(14)$ & $4(1)$ & $12(3)$ \\
\hline Total training & $496(100)$ & $464(100)$ & $537(100)$ & $519(100)$ & $351(100)$ & $343(100)$ \\
\hline
\end{tabular}




\section{What is already known on this topic}

Previous studies that have examined the level of injuries amongst elite rugby union players have reported the incidence of injury during match play but have not reported the incidence of injury during training or linked the incidence of injury to causation factors in competition and training.

suggested that training games involving skill based conditioning may provide a safer compromise, ${ }^{32}$ but this reduces the ability to control individual players' endurance training. The development of individual and team skills involving player to player contact is a fundamental element of training for forwards and backs; however, the high incidence of injury associated with contact training, in particular for backs, indicated that a review of this aspect of training could be beneficial in reducing the incidence of injuries. Finally, whilst fitness testing has many benefits, it should not place players at an unduly high risk of injury and, therefore, the structure of test protocols should also be kept under review.

\section{ACKNOWLEDGEMENTS}

The authors would like to acknowledge the work of M Lovell, who carried out the anthropometric measurements.

\section{Authors' affiliations}

J H M Brooks, C W Fuller, University of Leicester, Leicester LEI 7QA, UK S P T Kemp, D B Reddin, Rugby Football Union, Rugby Road, Twickenham TWI 1DS, UK

The authors would like to acknowledge the Rugby Football Union for their financial support of this research programme.

Competing interests: none declared.

\section{REFERENCES}

1 International Rugby Board, 2004. http://www.irb.com.

2 Nicholl JP, Coleman P, Williams BT. The epidemiology of sports and exercise related injury in the United Kingdom. Br J Sports Med 1995;29:232-8.

3 Bird YN, Waller AE, Marshall SW, et al. The New Zealand rugby injury and performance project: $\mathrm{V}$. Epidemiology of a season of rugby injury. $\mathrm{Br} J$ Sports Med 1998;32:319-25.

4 Garraway WM, Lee AJ, Hutton SJ, et al. Impact of professionalism on injuries in rugby union. Br J Sports Med 2000;34:348-51.

5 Targett SGR. Injuries in professional rugby union. Clin J Sports Med 1998;8:280-5.

6 Jakoet I, Noakes TD. A high rate of injury during the 1995 Rugby World Cup. S Afr Med J 1998;87:45-7.

7 Bathgate A, Best JP, Craig G, et al. A prospective study of injuries to elite Australian rugby union players. Br J Sports Med 2002;36:265-9.

8 Fuller CW, Drawer S. The application of risk management in sport. Sports Med 2004;34(6):349-356.

9 Noyes FR, Lindenfeld TN, Marshall MT. What determines an athletic injury (definition)? Who determines an injury (occurrence)? Am J Sports Med 1988; 16:65-8

10 Luthje P, Nurmi I, Kataja M, et al. Epidemiology and traumatology of injurie in elite soccer: a prospective study in Finland. Scand J Med Sci Sports 1996;6:180-5
What this study adds

The present study provides an analysis of training practices and the incidence and aetiology of injuries during competition and training for the 2003 England Rugby World Cup squad. Data are presented that define the severity of injuries to forwards and backs as functions of injury location, diagnosis, and causation factors.

11 Hodgson Phillips L, Standen PJ, Batt ME. Effects of seasonal change in rugby league on the incidence of injury. Br J Sports Med 1998;32:144-8.

12 Meeuwisse WH. Predictability of sports injuries. What is the epidemiological evidence? Sports Med 1991;12(1):8-15.

13 van Mechelen W. The severity of sports injuries. Sports Med 1997;24(3): 176-80.

14 Drawer S, Fuller CW. Evaluating the level of injury in English professional football using a risk based assessment process. Br J Sports Med 2002;36:446-51.

15 Hawkins RD, Fuller CW. A prospective epidemiological study of injuries in four English professional football clubs. Br J Sports Med 1999;33:196-203.

16 Orchard J. Orchard sports injury classification system (OSICS). Sport Health 1993; 11(3):39-41

17 Durnin JVGA, Rahaman MM. The assessment of the amount of fat in the human body from measurements of skinfold thickness. Br J Nutr 1967;21:681-9.

18 Lower T. Injury data collection in the rugby codes. Aust J Sci Med Sport $1995 ; 27(2): 43-7$

19 Finch CF. An overview of some definitional issues for sports injury surveillance. Sports Med 1997;24(3):157-63.

20 Hagglund $M$, Walden $M$, Ekstrand J. Exposure and injury risk in Swedish elite football: a comparison between seasons 1982 and 2001. Scand J Med Sci Sports 2003;13:364-70

21 Bahr R, Bahr IA. Incidence of acute volleyball injuries: a prospective cohort study of injury mechanisms and risk factors. Scand J Med Sci Sports 1997;7:166-71.

22 Meeuwisse WH, Sellmer R, Hagel BE. Rates and risks of injury during intercollegiate basketball. Am J Sports Med 2003;31(3):379-85.

23 Hawkins RD, Hulse MA, Wilkinson C, et al. The association football medical research programme: an audit of injuries in professional football. $\mathrm{Br} J$ Sports Med 2001;35:43-7.

24 Arendt E, Dick R. Knee injury patterns among men and women in collegiate basketball and soccer. NCAA data and review of literature. Am J Sports Med 1995;23(6):694-701

25 International Rugby Board. RWC 2003 - statistical review and match analysis, http://www.irb.com/playing/game+analysis.

26 Holmyard DJ, Hazeldine RJ. Seasonal variations in the anthropometric and physiological characteristics of international rugby union players. In: Reilly T, Clarys JP, Stibbe A, eds. Science and Football II. London: E \& FN Spon, 1993:21-6.

27 Tong RJ, Mayes R. The effect of pre-season training on the physiological characteristics of international rugby union players. J Sports $\mathrm{Sci}$ 1995; 13:507.

28 International Rugby Board. The laws of the game 2004, http:// www.irb.com/laws.

29 Almeida SA, Maxwell Williams K, Shaffer RA, et al. Epidemiological patterns of musculoskeletal injuries and physical training. Med Sci Sports Exerc 1999;31(8): 1176-82.

30 Ekstrand J, Walden $M$, Hagglund $M$. Risk for injury when playing in a national football team. Scand J Med Sci Sports 2004;14:34-8.

31 Gómez JE, Ross SK, Calmbach WL, et al. Body fatness and increased injury rates in high school football linemen. Clin J Sport Med 1998:8(2):115-20.

32 Gabbett TJ. Training injuries in rugby league: an evaluation of skill-based conditioning games. J Strength Cond Res 2002;16(2):236-41. 